When this paper was first written, a year ago, it appeared to me that here was an opportunity of obtaining uniformity of practice, at any rate in the British Isles. I then considered that an eflort should be made to get all British ophthalmic hospitals to adopt the contra-international mode, as it would bring about the least possible disturbance; fifty-one institutions only would have to change their systems, leaving 70 practically unchanged.

There are now, however, other factors to be considered. The relationship of the United States of America has been intimate, and is likely to become so still more.

In the American edition of "Fuchs's Ophthalmology," Duane states that the prevailing system there is the standard (Fig. F.) although with the axis number appearing on the upper semicircle.

Again, the Standard (Fig. E.) is now, I believe, the only one in use in the British Army, and in the optical trade no other system is employed. Prescriptions are always converted into Standard notation before they are actually made up. The Standard has the great advantage that the degree number is the same for both eyes, and therefore, in ordering, merely the strength and the axis number is required. Prescriptions by telegram are thus simplified. It is purely mathematical. The Standard system certainly does not conform with the anatomical idea of symmetry, but such theoretical considerations will have to be waived if the easiest path to uniformity in this country and America is to be taken.

The subject is one which the newly formed Council of British Ophthalmologists ought to consider, and with the weight of its prestige induce uniformity in all institutions, at any rate, in the United Kingdom. The only difterence being that here it is usual to think of the numbers in the lower semicircle, whereas in America the upper is used.

\title{
IODINE IN INFLAMMATION OF THE EYE
}

\section{Pichard KerRy, M.D.,}

OCULIST TO THE WESTERN AND CHILDREN'S MEMORIAL HOSPITALS, MONTREAL

THE hypodermic use of iodine in inflammatory conditions of the eye, has, in the writer's experience, yielded consistently satisfactory results for a number of years past, particularly in septic iritis and in tuberculosis of the eye. The drug apparently acts by dispersing inflammatory foci, thus producing relief from pain which is a great boon to the patient, and which alone would justify its use, quite independently of its curative effect.

The cases detailed below show some interesting and important results and are here recorded to illustrate what may be accomplished by the use of iodine hypodermically. 
CASE 1.--A woman, aged 40 years, lefteye absolute glaucoma, right eye seriously impaired, vision about $6 / 18$, came for treatment seven or eight years ago. A $3 \mathrm{~mm}$. hole was punched in the sclera with a dental engine and trephine; Elliot's operation had not then been published, and vision returned to normal. She came again three or four years afterwards complaining of pain and loss of sight; there were hypertension, ciliary injection, and cloudiness of the media. She was given a hypodermic of iodine and returned in three days with all signs and symptoms simply abolished. In about two weeks she was back again with a recurrence, all symptoms being much more severe than during the previous attack. She was again given iodine and directed to have a number of decayed teeth extracted. All signs again disappeared; the eye became quiet and normal vision returned. During the past autumn, about three years after the last attack, she came again, the eye being unfortunately quite blind. In the writer's absence she had come to the hospital and, not finding him, had gone elsewhere. An iridectomy had been done but the anterior chamber had not reformed and the tissues about the wound were matted in exudate. Had this case been treated as previously with perhaps a trephine operation in addition, the sight would probably have' been preserved.

CASE 2.-A woman of thirty-five in robust condition, had all the usual signs of glaucoma, vision $\frac{6}{36}$ to $\frac{6}{24}$. The symptoms were quite severe, and the inability to use the eyes, even when wearing her glasses, was very marked, and caused great distress. Refractive error was 2.5 of hypermetropia in each eye. She had been wearing +2 , but was given +3 for temporary use and eserin and massage were ordered.

There was some initial improvement but this was not maintained, so she was given an injection of iodine, once a week for four weeks. At the end of this period vision for distance was normal. Little weakness of focussing power was left, and she was using the eyes without distress. She did not report again for nearly a month. The eyes were now rather sensitive to light but were causing no trouble during near work. This patient had marked gingivitis, both upper and lower gums being involved. X ray examination showed absorption at the root of a left upper bicuspid, which was also carious, a similar condition at the root of the right canine tooth was thought to be present, but as the changes were slight there was some doubt of this.

Treatment for the gums was ordered early but the bicuspid, the principal offender, was not extracted until her return after Christmas, so that the improvement in the eyes took place despite the presence of the principal exciting cause.

Cultures taken from the root of the tooth and the cavity showed in one instance almost pure streptococci with a few staphylococci, in 
the other staphylococci in almost pure culture. The tooth in broth gave in addition bacillus coli and some saprophytes.

So long as there is no sign not be considered in this case.

The comparison of the results in these two cases with those obtained in iritis suggests a similarity in the cause of the two diseases.

If glaucoma can be proved to be septic in origin, the infection must be of a different type from that found in iritis, and the second case quoted suggests the presence of mixed infection. There are a number of clinical and pathological observations which tend to show that glaucoma is septic, and that the hypertension is due to blocking of the emunctories from the eyeball.

Although these considerations are partly theoretical they correlate glaucoma rationally with the other inflammatory conditions of the uvea and are in remarkable agreement with the conclusions reached by Martin Fischer, from entirely different d ${ }^{\star} \mathrm{a}$, and published in his illuminating book, "Oedema and Nephritis."

CASE 3.- The next case is interesting because of the marked result obtained from one dose only. Three years ago the patient, a well known man of fifty odd years, had been below par for some months. His physician stated that he had "slow tuberculosis," the lesion being pulmonary. On being questioned by a friend, he suddenly found that he could not see with the left eye

Examination showed quiet iritis, vision P.L. only. The eye was painless with slight ciliary injection, cornea fairly clear, aqueous turbid, iris details indistinct, the pupil was contracted and both secluded and occluded; in the anterior chamber was an exudate membrane which had evidently covered all the anterior surface of the iris and the pupil ; it had become detached above and the upper third was folded downwards and hanging in the chamber. The condition undoubtedly justified a serious prognosis. He was given an injection of iodine. Next day the aqueous was clear; on the second day the membrane had almost completely disappeared and on the third day there was a well dilated pupil, atropin of course being used. Subsequently the disease took on a more acute form with pain, injection, and the formation of some posterior synechiae, but the symptoms were not severe. In about two months conditions were practically normal and there has been no trouble since.

The effect of iodine is most marked in attacks of acute inflammation. The following two cases show, however, that its action in chronic cases is also marked and indicate that the leucocytes and connective tissue are most affected.

CASE 4.-A girl, aged about twenty years; right eye lost from ophthalmia neonatorum, left almost completely covered with a dense leucoma from the same cause, hiding all details of the iris and pupil. She was treated irregularly for two years (being absent during the 
summer months), at times once a week at others once a fortnight. At present the leucoma is less than half its former size; a healthy looking iris can be seen through the upper part of the cornea, which is perfectly clear. The lower part of the cornea, however, does not clear, the opacity here being due to alteration in the corneal tissue, while above there has apparently been only cell infiltration.

CASE 5.-A man, aged 50 years, under treatment for syphilis for two years; blood reported negative. Right eye practically no vision, due to macular involvement. The left eye showed almost complete disappearance of the vessels of the fundus in a mass of exudate which covered them; two short lengths of vessel, equal to about three-quarters of the diameter of the disc in extent, alone were visible. This was a marked example of the condition which some authorities term retinitis proliferans, and was the most extensive syphilitic alteration of the vessels that the writer has seen. The vision, which was less than $6 / 60$, rose to $6 / 18$ under iodine treatment, and then receded, the deterioration being accompanied by pigmentary changes in the macular region. The interesting feature in this case is the marked absorption of the exudate in the fundus which has occurred; the dense white tracts are much thinner and smaller, and, where the exudate has disappeared, dark brownish red cords run across the fundus showing the vessels quite empty. With such complete vascular disorganization it is, perhaps, not surprising that the vision could not be saved. Another interesting feature in this case is that during the time when his sight was relatively good and treatment had been remitted for some time, he came in one day with acute inflammation of the eye, the condition resembling closely that which obtained in the first glaucoma case. On resuming the iodine the condition disappeared with the same rapidity as in the other case.

As we have a reasonable amount of evidence as to the marked activity of iodine, a somewhat more detailed examination of its action in these cases will enable the reader to appreciate more completely its effects, and to use it to greater advantage. In addition to the marked stimulation to glandular secretion and activity in the tissues which it causes, iodine, by its power of removing cell infiltration in inflammatory cases, disembarrasses the circulation. By this means it disperses focal infection, and throws infective material and inflammatory products into the blood. Where the initial lesion is not extensive no constitutional reaction is observed. In more extensive lesions, in a case, for example, of an old disease of the knee joint with atrophy, its use has caused a condition resembling grippe for a day or so. In the still more extensive lesions found in pulmonary tuberculosis, with a relatively large diseased area, acute toxaemia will result, which may prove fatal. The effect of one dose only of one quarter of a grain 
in an adult, as instanced in several of the cases quoted, is very remarkable.

The solution used in the cases reported is iodine in sesame oil, one to forty. Ten minims are injected once a week, occasionally twice. If injection is made into the skin an induration results, which will last a long time, but causes no inconvenience. If into the subcutaneous tissue there is usually nothing noticeable after a week; intramuscular injection would probably cause more severe reaction, but it has not been used by the writer. Occasionally sharp local reactions develop, or the effect may be felt all through a limb, but this quickly subsides.

The results obtained from the routine use of iodine in iritis and tuberculosis of the eye, quite apart from those obtained by the writer in a large number of other cases, aftord more than sufficient evidence of the great usefulness of this method of using the drug. The fact that it is injected hypodermically, and thus acts constitutionally, indicates that its use may be greatly extended, and it has already proved a most useful remedy in the hands of the general practitioner.

\title{
NOTE ON AN EARLY CASE OF MULES'S OPERATION
}

\author{
BY \\ HAROLD GRIMSDALE, \\ LONDON.
}

THE statement sometimes made that the globe in Mules's operation always eventually escapes, suggests the publication of the following note :

Mary D. was admitted into St. George's Hospital under the care of the late Mr. R. Brudenell Carter, on August 24, 1888, on account of a painful blind eye. The cause of the blindness is stated to have been iridocyclitis.

Three days later Mr. Carter performed Mules's operation. The wound was closed by a single layer of sutures; the line of closure was horizontal. The course of healing was uneventful, according to the notes, and the patient left the hospital with the glass globe well covered.

She came to St. George's Hospital on July 12, 1919-almost 31 years after the operation-for glasses for the right eye. Recognizing from the appearance that the original operation probably had been Mules's, I made enquiries and was able readily to find the original notes.

The stump is well covered; the globe with the enclosing sclerotic is about $15 \mathrm{~mm}$. in diameter and the movements are very good. She has always worn a glass shell eye without trouble. 